Georgetown University Law Center

Scholarship @ GEORGETOWN LAW

1993

\title{
Foreword: Health Care Reform in the United States-The Presidential Task Force
}

Lawrence O. Gostin

Georgetown University Law Center, gostin@law.georgetown.edu

This paper can be downloaded free of charge from:

https://scholarship.law.georgetown.edu/facpub/758

19 Am. J.L. \& Med. 1-20 (1993)

This open-access article is brought to you by the Georgetown Law Library. Posted with permission of the author. Follow this and additional works at: https://scholarship.law.georgetown.edu/facpub

Part of the Health Law and Policy Commons, Health Policy Commons, Insurance Law Commons, and the Public Health Commons 


\title{
Foreword: Health Care Reform in the United States - The Presidential Task Force
}

\author{
Lawrence $\mathrm{O}$. Gostin†
}

The United States is on the verge of major health care reform. Hillary Rodham Clinton has led a cabinet-level task force, assisted by a large health policy committee. During the 1992 Presidential campaign, Bill Clinton rejected previous reform proposals that focused on a single-payer health insurance system modelled on the Canadian system, ${ }^{1}$ or on a system in which employers would be required to provide health insurance or pay into a fund for the uninsured ("pay or play"). ${ }^{2} \mathrm{Mr}$. Clinton proposed a system of "managed competition," 3 first developed by the Jackson Hole group in the late 1970s. ${ }^{4}$ The Presidential Task Force on Health Care Reform built on the concept of managed competition by combining it with global expenditure budgets.

Managed competition restructures the market for health care services into competing, prepaid health plans, giving providers built-in incentives to offer a comprehensive benefits package at the lowest cost. ${ }^{5}$ It is a purchasing strategy that uses rules for competition to award more subscribers and reve-

† Executive Director, American Society of Law, Medicine \& Ethics. Mr. Gostin is a Visiting Professor at Georgetown University Law Center, and at the Johns Hopkins School of Hygiene and Public Health. He is also a member of the Presidential Committee on Health Care Reform. The views presented in this Essay do not represent the findings or conclusions of the Presidential Committee.

I See, e.g., Steffie Woolhandler \& David U. Himmelstein, A National Health Program: Northern Light at the End of the Tunnel, 262 JAMA 2136 (1989); see also Kevin Grumbach et al., Liberal Benefits, Conservative Spending, 265 JAMA 2549 (1991); Paul D. Wellstone \& Ellen R. Shaffer, The American Health Security Act - A Single-Payer Proposal, 328 New Enc. J. MEd. 1489 (1993).

'See, e.g., John D. Rockefeller IV, A Call For Action: The Pepper Commission's Blueprint For Health Care Reform. 265 JAMA 2507 (1991); see also General Accounting Office, Access to Health Care: States Respond To Growinc Crisis 32-35 (June 1992) (describing the Massachuselts "pay or play" plan enacted in 1988).

${ }^{3}$ See generally Bill Clinton, The Clinton Health Care Plan, 327 NEw ENG. J. MED. 804 (1992) (for an overview of the Clinton Health Care plan, as proposed during the 1992 Presidential campaign).

${ }^{4}$ See generally Alain C. Enthoven, Consumer-Choice Health Plan: A Vational Heallh Insurance Proposal Based on Regulated Competition in the Private Sector, 298 NEw EnG. J. MED. 709 (1978) (detailing the Jackson Hole group's proposal).

5 See American Medical Peer Review Association, Managed Competition and the Role OF QUality OVERSight (Mar. 1993). 
nues to those health plans that provide higher quality care at a lower cost. ${ }^{6}$

Scholars have presented compelling critiques of the current health care system on philosophical, ${ }^{7}$ public health, ${ }^{8}$ and financial ${ }^{9}$ grounds. The system has failed to provide universal access to health care with an equitable sharing of benefits and burdens. An estimated thirty-seven million people do not have health care coverage, with many more people inadequately covered. ${ }^{10}$ Disparities in access to health care have been shown on grounds of socioeconomic status, ${ }^{11}$ race and ethnicity, ${ }^{12}$ and gender. ${ }^{13}$

The current system has also failed to control escalating health care costs relative to health care expenditures in other countries. The United States spent more than $\$ 666$ billion on health care in 1990 , approximately $12 \%$ of the nation's gross national product ("GNP"). ${ }^{14}$ Health care expenditures are projected to reach $\$ 1.6$ trillion, between 16 and 18 percent of the gross domestic product ("GDP"), by the end of the decade if effective controls are not instituted. ${ }^{15}$ These figures stand in stark contrast to the percentage of GNP that is devoted to health care in countries such as Canada, Germany, Great Britain, and Japan; they devote from $5.8 \%$ to $8.7 \%$ of their GNP to health care. ${ }^{16}$

Economists have repeatedly pointed to the reasons for escalating costs in the U.S. health care system: (1) high administrative costs fueled by bewildering numbers of third-party payers, ranging from government programs, such as Medicaid and Medicare, to not-for-profit and for-profit insurers, each with its own reimbursement policies, reviews, and paperwork; ${ }^{17}$ (2) lack of global budgets at the federal, state, or local levels, and a lack of systematic policies

${ }^{6}$ Alain C. Enthoven, The History and Principles of Managed Competition. Health AfF., Supp. 1993, at 24, 29 [hereinafter Mistory and Principles].

7 See, e.g., Norman Daniels, Jus'r Health Care (1985).

${ }^{8}$ See, e.g., H. Denman Scotl \& Howard B. Shapiro, Universal Insurance for American Health Care, 117 Annals Internal. Med. 511 (1992).

9 See, e.g., Robert J. Blendon et al., The Heallh Insurance Industry in the Year 2001: One Scenario, Health Aff., Winter 1991, at 170.

${ }^{10}$ BNA, Number of Uninsured Persons Increases to 36.6 Million in 1991, Daily Labor ReP., Jan. 12, 1993, available in LEXIS. Nexis Library, Omni File (reporting results of the Employee Benefit Research Institute Study).

11 See Paul H. Wise et al., Racial and Socioeconomic Disparities in Childhood Mortality in Boston, 313 New ENG. J. MEd. 360, 364 (1985).

12 See Council on Ethical and Jud. Aff., Black-White Disparities in Health Care, 263 JAMA 2344 (1990).

${ }^{13}$ See John Z. Ayanian \& Arnold M. Epstein, Differences in the L'se of Procedures Betueen Women and Men Hospitalized for Coronary Hearl Disease, 325 New ENG. J. MED. 221, 223-25 (1991).

${ }^{14}$ Louis W. Sullivan. The Bush Administration's Health Care Plan, 327 NEw ENG. J. MEd. 801, 801 (1992).

15 See Sally T. Sonnenfeld et al., Projection of National Health Expenditures Through the Year 2,000, Health Care Fin. Rev., Fall 1991, at 1, 4, 22; see also Congressional Budget Off., Projections of National Health Expenditures 14 (Table 1) (Oct. 1992).

${ }^{16}$ See George J. Scheiber et al., Health Care Systems in Twenty-Four Nations, Health Afr., Fall 1991, at 22, 24. These cost projections are examined with great clarity in Timothy S. Jost \& Sandra J. Tanenbaum, Selling Cost Containment, 19 AM. J. L. \& MED. 95, 96-97 (1993).

17 See Steffie Woolhandler \& David U. Himmelstein, The Deteriorating Administrative Efficiency of the U.S. Health Care System, 324 NEw ENG. J. MED. 1253, 1255-56 (1991) (19 to 24 percent of health care expenditures goes toward administrative expenses, including those of the nation's insurance companies). 
for prudent allocation of resources based on the cost-effectiveness of treatments; (3) escalating use of advanced technology, such as imaging machines and bone marrow transplants, without systematic outcomes research that demonstrates its benefits relative to costs; and (4) few incentives for choosing lower-cost alternatives at the point of service because consumers seldom bear, or are even completely aware of, the actual costs of treatment. ${ }^{18}$

Failure to control health care costs has ethical as well as economic implications. The amount that a nation can afford to spend on a wide range of services is limited. While resource allocation decisions are highly complex, as a general matter, imprudent allocation of health care resources can detract from resources for equally important services, such as housing, food, education, and social services.

While it is relatively easy to criticize the current health care system in the United States, constructing a new one is fraught with complexities and tradeoffs. The plan proposed by the Presidential Task Force should be measured against the two overarching goals that drove the reform efforts: providing high-quality care while controlling escalating costs, and providing universal access with an equitable sharing of benefits and burdens. This Essay focuses on the objectives of universal access, equity, justice, and choice. In particular, $I$ inquire as to whether the design features of the new system are likely to fulfill these objectives.

\section{DESIGN FEATURES OF THE NEW SYSTEM}

As this Symposium went to press, President Clinton had not made the design decisions for health care reform. The exact specifications of the new health care system depend on the package that the President will send to Capitol Hill and the changes that Congress will make in the reform package. Some of the basic structures and organizing principles of the new system that are being considered by the President are already the subject of intense public scrutiny.

The design being considered would involve new relations between the federal government and the states, between the public and private sectors, and between health care financing and delivery. ${ }^{19}$ The federal government would establish the parameters of the new system through national legislation, regulation, and guidelines, with implementation occurring principally at the state level. State flexibility would become a hallmark of the new system, with states having considerable leeway in implementation. Provided that states follow national parameters (as described below), they probably could establish very different kinds of health care systems, ranging from a single payer to managed competition within a budget. Given the strong preference among many health policy experts for a single-payer system, ${ }^{20}$ it is extremely important to emphasize the states' authority to implement such a system. A

18 See History and Principles, supra note 6, at 25-27; see also Charles Weller, "Free Choice" as a Restraint of Trade in American Health Care Delivery and Insurance, 69 Iowa L. Rev. 1351 (1984) (exploring how patients are isolated from the competitive aspects of the health care market).

19 See Paul Starr \& Walter A. Zelman, Bridge to Compromise: Competition L'nder A Budget, Health AfF., Supp. 1993, at 7, 9.

${ }^{20}$ For a related discussion about single-payer systems, see supra note 1. 
large state, for example, might consider establishing a system of managed competition in urban areas, and a single-payer system in rural areas where effective competition is constrained by the small number of consumers and providers.

The new system will provide the right to health care to all citizens and lawful residents of the United States, all of whom will receive health security cards, transferrable to any area of the country. The card would also guarantee access to health care independent of employment or other eligibility criteria. Therefore, the new system will address the American public's concern for long-term security in health care - coverage would be portable and move with the individual if he or she changed jobs or lived in another part of the country.

\section{A. New System Structures}

The basic structures being considered for the new system are the National Health Board, Health Alliances, and Accountable Health Plans ("AHPs"). Broadly speaking, the National Health Board would establish federal parameters for purchasing, providing, and accessing care in the new system; Health Alliances would, on behalf of consumers in their regions, contract with plans to provide high-quality, low-cost care within their budgets; and AHPs would provide care on a prepaid, per capita basis.

\section{National Health Board}

The National Health Board is likely to be a quasi-governmental authority (perhaps structurally similar to the Securities Exchange Commission), established at the federal level, with members appointed by the President. It would provide or implement federal standards for the overall design and operation of the new system. Its functions would include: determining a comprehensive benefits package that might change over time; establishing national, state, and/or Health Alliance budgets; setting rules for managed competition that protect the interests of consumers; setting rules and guidelines for the prudent allocation of resources, particularly for highly expensive treatments that provide little benefit; and establishing a uniform data reporting system to help measure the performance and quality of competing health plans. The National Health Board might establish panels on specialized areas, such as ethics, data protection (privacy), or public health.

\section{Health Alliances}

Health Alliances are conceived as aggressive purchasers of health plans on behalf of large numbers of consumers. At an earlier stage in Task Force deliberations and in relevant literature, they were referred to as Health Insurance Purchasing Cooperatives ("HIPCs") or Purchasing Cooperatives." 1 Health Alliances would act as collective purchasing agents for all consumers in the new system. Medicaid recipients will likely be "folded into" the new

${ }^{21}$ See generally Walter A. Zelman, Itho Should Govem the Purchasing Cooperative?, Health Arr., Supp. 1993, at 49 . 
system. Large employers (with 1,000 or more employees) will probably be permitted to "opt out" of the Alliance system or act as their own Alliance.

At least one Health Alliance will operate in each state, with perhaps 100 Alliances throughout the country. Alliances would be subject to state regulation, perhaps organized as not-for-profit organizations. Alliances would not deliver care or directly pay providers. They would contract with a number of health plans, including Health Maintenance Organizations ("HMOs"), Preferred Provider Organizations ("PPOs"), and a traditional free-choice-of-provider indemnity plan. Since Health Alliances would control a dominant part of the market for health care services in their regions, they should be able to negotiate strongly for lower-cost, higher-quality services for consumers.

\section{B. New System Financing}

Financial contributions for the new system will be shared by employers, consumers, and government. The most likely option would be for each Health Alliance to set an annual, community-rated premium based on the least expensive plan in the region that provides a satisfactory standard of care ("the benchmark plan"), or on a weighted average of the least expensive plans. The Health Alliance would pay no more than this benchmark premium. Consumers who choose to enroll in more expensive plans would pay the marginal difference in cost. Employers would be required to pay a minimum share of the premium for health coverage (e.g., $75 \%$ ) for employees and their dependents, although they could choose to pay more. Employees would pay the remaining portion of the premium. To ensure that health coverage is affordable for employers and employees in low-wage industries, a cap would be set on the amount paid (e.g., $7 \%$ of payroll for employers and $2 \%$ of family income for employees). ${ }^{22}$

Unemployed, self-employed, and part-time workers would also be required to contribute. However, federal government subsidies would be available for low-income individuals and families. Government subsidies would be based on a sliding scale that has yet to be developed. Government, for example, might pay the full premium for persons at or below the poverty line, with diminishing payments for those up to $200 \%$ of the poverty line. ${ }^{23}$ Separate streams of federal funding would be provided for those with special needs for example, disabled persons and the very poor who are currently on Medicaid and are eligible for some long-term care. The additional amount of federal revenues needed to fund the reform package has been estimated at around $\$ 100-\$ 150$ billion per year. ${ }^{24}$ However, this amount may be offset by the amount already spent on acute care under Medicaid (approximately $\$ 62$ billion). ${ }^{25}$

22 Starr \& Zelman, supra note 19, at 17.

23 Clearly, the government could be less generous, offering a full subsidy for those at or below $50 \%$ of the poverty line, with diminishing payments for those up to the poverty line.

24 See Robert Pear, Healih Care Costs .May Be Increased S100 Billion A Year, N.Y. Times, May 3, 1993, at Al [hereinafter Health Care Costs].

25 See John F. Sheils et al., Potential Public Expenditures C'nder Managed Competition, Health Afr.. Supp. 1993, at 229, 231, 239; Starr \& Zelman, supra note 19, at 17; see also John K. Iglchart, The American Heallh Care System - Medicaid, 328 New ENG. J. MEd. 896 (1993). 
While health care reform places additional financial burdens on the federal government, principally to provide universal coverage for low-income persons, it provides financial benefits to the states. The principal benefit would be the phasing in of Medicaid's acute-care provisions to the new system. ${ }^{26}$ Additionally, public hospitals and clinics that provide uncompensated emergency care for the uninsured will have a considerably lighter burden. Persons with good health care will presumably become more productive citizens who are better able to work. This, in turn, ought to reduce state welfare costs. Finally, Hillary Rodham Clinton has announced an intention to fold the health care components of workers' compensation and automobile insurance into the new system, with concomitant savings to states, employers, and consumers. ${ }^{27}$

\section{Organizing National Principles for Health Care Reform}

While states will have substantial flexibility in implementing the new health care system, all participants will have to abide by the key organizing principles of reform. These principles will likely be part of a federal statute proposed by President Clinton that will preempt contrary state legislative provisions. Federal law that is inconsistent with the new plan, such as various portions of the Employee Retirement and Income Security Act ("ERISA"), ${ }^{28}$ are also likely to be overridden. ${ }^{29}$

\section{Universal Coverage}

After a phase-in period, all citizens and lawful residents of the United States would be entitled to health care coverage either within the new system or through other federal programs, such as Medicare. To avoid a "free rider" problem, all eligible persons will be required to enroll in an accountable health plan and pay the designated premium. ${ }^{30}$

\section{Open Enrollment}

All health plans that participate in the system would have to be open to all persons who hold health security cards and choose to be in the plan, subject to space limitations. An open-enrollment period would probably occur annually. No conditions based on health status or other risk-selection criteria would be permitted. While health plans may have geographic catchment areas, they would not be permitted to gerrymander their areas to avoid certain populations because of their risk profile, race, or socioeconomic status.

\footnotetext{
20 Sheils et al., supra note 25 , at 239.

27 Sep Robert Pear, Health Care Plan to Cover Injuries on Job and Roads, N.Y. Times, May 8, 1993 , at Al.

2\$ 29 U.S.C.A. \$\$1001-1461 (West 1985 \& Supp. 1993).

29. Sep Wendy K. Mariner, Problems with Employer-Provided Health Insurance - The Employee Retirement Income Securily dot and Health Care Reform, 327 NEw ENG. J. MED. 1682, 1685 (1992); see also Lawrence O. Gostin \& Alan I. Widiss, What's I'rong with the ERIS.A I'acuum?: Employers' Freedom to Limit Healıh Care Coverage Provided by Risk Retention Plans, 269 JAMA 2527, 2529-31 (1993).

${ }^{30}$ If a person who is not enrolled needs health services, some attempt to collect current premiums and recoup past premiums would probably be built into the system.
} 


\section{Community Rating}

Health plans will not be able to exclude, or to differentiate according to treatment or charges, any individual or group, regardless of medical condition. Plans will be required to use community rating. Under community rating, premiums are based on expected costs for all persons in the community, not on a particular group's historical costs (known as experience rating). Consequently, plans will not be permitted to charge higher premiums for persons who are older, sicker, poorer, or disabled. Health plans will not be allowed to use pre-existing condition provisions or discriminate against persons who have had, currently have, or are predicted to have higher health care costs.

The amount of money paid to health plans, however, would be risk-adjusted to cover the real costs of taking care of higher-risk patients, such as those with chronic disease. If health plans are paid approximately the true cost for patients with AIDS, cancer, heart disease, or schizophrenia, for example, they may be more likely to structure the delivery of services to provide specialized, expert, or intensive care for chronic, costly diseases. Health plans would no longer have an incentive to hire too few or inexperienced infectious disease practitioners to discourage persons with HIV infection or disease from joining their plan. The National Health Board would set specifications for risk adjustment.

\section{Comprehensive Benefits Package}

All health plans would be required to provide the same standard health benefits package. The package is not intended to offer minimal services, but rather a reasonably robust set of benefits. The benefits package would include clinical prevention services, acute-care services, hospitalization, mental health services, alcohol and drug dependency services, outpatient services, emergency care, prescription drugs, and a scaled-down version of dental care. Long-term care would remain uncovered, except for very limited services, but poor or disabled populations could be reimbursed under separate funding streams.

There are three justifications for a national, uniform benefits package. First, such a package guarantees Americans all reasonable health care services necessary to promote health, prevent and treat sickness and disease, and alleviate pain and suffering. Second, a uniform package is intended to facilitate competition among plans and informed choice among consumers. At present, consumers have great difficulty choosing among health insurance plans because the confusing array of benefits that each plan provides makes comparison virtually impossible. If plans offer the same benefits package, they must ensure quality and a fair price in order to compete. If consumers can be assured a uniform benefits package, they can compare plans based on quality and cost. Third, the uniform package prevents plans from withdrawing services for risk-selection purposes. For example, it would prevent plans from offering inferior or no benefits to drug-dependent or mentally ill persons with the intention that these individuals will choose other plans.

Of course, the services that health plans offer are still vulnerable in the new system. While all plans must provide a uniform benefits package, the 
actual services offered in the same package can vary widely. Indeed, one might expect the services to be better in more expensive plans than in the benchmark (i.e., least expensive) plan. More expensive plans might have more modern and a greater number of laboratories, imaging machines, and other equipment and services; more experienced and a greater number of specialists; and shorter waiting times for services. While some of these "extras" may or may not improve quality, the plans will be perceived as "better" even though they provide the same benefits package. The success of the new system will depend, in part, on whether differences in services among plans have more to do with convenience and comfort (e.g., longer waiting times in non-emergency cases or nicer carpets) than with the quality of health services (e.g., lower morbidity and mortality resulting from better treatment outcomes).

\section{Quality Assessment}

To help ensure the overall quality of services that health plans offer, and to promote effective consumer choice, the National Health Board and Health Alliances would routinely measure the quality of services that health plans offer. The National Health Board, for example, would require quality measurements in the form of a "report card" that all Health Alliances would publish and make available to consumers.

The report card might measure: (i) consumer satisfaction (e.g., percentage of enrollees satisfied with the plan or satisfied with their primary care physician, percentage of enrollees leaving the plan, and the number of complaints filed); (ii) access to care (e.g., waiting times to see primary care physicians and specialists); (iii) clinical prevention services (e.g., rates for vaccinations, mammograms, prenatal care, HIV or tuberculosis screening); and (iv) outcomes (e.g., percentage of low birth weight infants, nursing home or hospital patients with bedsores, or mortality after a heart attack or stroke).

Quality assessment, of course, is far more complicated than a short "report card" can reflect. Differences in outcomes can reveal differences in standards of care, or differences in patient profiles. Quality measurements that might be informative for one population may be inadequate for another. For example, a plan may receive an overall high satisfaction rating, but the rating may be very low among underserved groups, such as disabled or mentally ill persons.

Finally, measurement standards will need to change over time. Some plans that offer excellent care may perform less well on the indicators that happen to be used in any given year. At the same time, plans might "game" the system by channelling resources only to measured areas. The result would be high marks on the "report card," but otherwise inferior quality services.

\section{ETHICAL FOUNDATIONS OF HEALTH CARE REFORM: MEASURING THE NEW SYSTEM AGAINST KEY ETHICAL VALUES}

One of the most interesting features of the health care reform process has been Hillary Rodham Clinton's establishment of a cluster on "Ethical 
Foundations of the New System" in the Presidential Working Group. ${ }^{31}$ The "Ethical Foundations" Cluster identified fifteen ethical values and principles for the new health care system: (i) health care's fundamental ethical importance (providing opportunities for a decent life); (ii) universal access (without financial or non-financial barriers); (iii) comprehensive benefits (to meet the full range of health care needs); (iv) equal benefits (differences in care reflecting differences in needs, not individual or group differences); ( $v$ ) communal sharing of risks (spreading uneven costs and burdens of meeting health care needs across the entire community); (vi) progressive financing (payments for health care based on ability to pay); (vii) intergenerational solidarity (meeting needs at each stage of life and equitably sharing benefits and burdens across generations); (viii) prudent allocation of resources (wise allocation of resources to favor cost-effective health care services over other important, competing social goods); (ix) efficacious treatments (services of established efficacy and benefit, with research to assess current medical interventions and produce innovative treatments); $(x)$ high-quality services (research and monitoring to assess quality and provide information for informed consumer choice); (xi) administrative efficiency (minimizing administrative complexity and expense); (xii) individual choice (protecting, respecting, and facilitating effective individual choice about health care, including choice of plans, health care professionals, and delivery of services); (xiii) responsibility for health (encouraging and facilitating individual responsibility for protecting and promoting a person's own health and the health of the family); (xiv) professional integrity (respecting the expertise and integrity of health care professionals and protecting the health care professional-patient relationship); and (xv) procedural fairness (fair, open, and democratically accountable design, operation, and governance of the health care system, including fair grievance procedures).

Using these and other ethical values as yardsticks for the design and future operation of the health care system provides a built-in standard for objective, ongoing assessment of the reform efforts. Elucidating each of these values and measuring the design features of the new system against them is a complex and time-consuming, but necessary task. Here, I provide only a sketch of the arguments on a few of the most important issues: access, equity, justice, and choice. These ethical values already have strong intellectual foundations in philosophical literature. ${ }^{32}$

\section{A. Universal ACCess}

Health care is considered a fundamental good because of its efficacy in protecting and restoring physical and mental functioning, preventing sickness and premature death, and alleviating pain and suffering. Health care, therefore, is indispensable to afford individuals the opportunity to enjoy life. Each

3) The ideas for Section II were generated collectively by Cluster 17 ("Ethical Foundations") of the health policy working group, chaired by Nancy Dubler and Marion Secundy. My gratitude goes to all members of this Cluster.

32 See Reinhard Priester, A l'alues Framework for Health System Reform, Health Aff., Spring 1992, at 84, 105 (proposing fair access as the "preeminent value" of U.S. health care). For general analyses of ethical frameworks, see Daniels, supra note 7 . 
person has an ethical claim to a fair share of health care resources without unreasonable financial or non-financial barriers. The system should offer comprehensive services to meet the full range of health care needs, independent of the economic, social, racial, or other personal status of the individual or group.

Formidable barriers to access to health care exist in America. Major impediments are erected by financing arrangements that are inadequate to reimburse individuals for health care. Many non-financial barriers are also present, and include geographic isolation, racial or gender discrimination, linguistic and cultural barriers, and poorly planned distribution of services and providers.

The health care reform bill will focus primarily on financial barriers to access. The new system would guarantee all citizens and lawful residents the right to a health security card and the right to enroll in a health plan that provides a comprehensive benefits package. These rights are afforded to individuals regardless of ability to pay, employment status, pre-existing conditions, or other risk factors. The plan, therefore, establishes a system that would substantially remedy the central financial barriers to health care access. Under the plan, a federal subsidy would pay for health coverage for the poor; coverage would be guaranteed should an individual leave a job or move to another part of the country; and persons could not be denied coverage or have coverage capped or withdrawn if they were or became sick.

The central trade-off in providing coverage for the millions of individuals who are currently uninsured or underinsured is the monetary cost (estimated at between $\$ 100-\$ 150$ billion), ${ }^{33}$ as well as the political costs of proposing new taxes. A likely compromise would be to phase federal subsidies into the system and provide less generous subsidies for the poor. These dual policies - "phase-in" and smaller subsidies - pose the most significant problems in achieving the ethical value of universal access to health care.

The currently uninsured are not likely to obtain immediate coverage under the new system. A phase-in period ranging from one year to an unspecified future time could be considered. Suppose the phase-in period were to take place shortly before or after the next Presidential election, or that the date for bringing the poor into the new system was left unspecified (e.g., until sufficient cost savings were obtained from the new system). This would leave the poor vulnerable to both the political process and the efficiency of the new system.

Political judgments about providing an entitlement to the poor vary considerably over time and across political parties. A real risk exists that the poor would never be brought into the new system or would be subject to inordinate delays. The most disturbing scenario would link the future entitlements of the poor to the realization of cost savings under the new system. Since the proposed system of managed competition is not based on extended experience in other countries or at the state level, the amount of savings is difficult to determine. Even if savings are apparent, it is uncertain who would be the new system's winners and losers. If most of the savings accrue to the states,

${ }^{33}$ See Health Cave Costs, supra note 24. 
public hospitals, or the insurance industry, the federal government will not necessarily end up in a better position to finance the uninsured. If the federal deficit remains high due to increases in spending in other areas and/or a failure to obtain sufficient increases in revenue sources, the health of the poor would become a hostage to the political process. Universal access to health care without financial barriers represents the moral core of health care reform. Perhaps the single most important design feature would be folding the uninsured into the new system within a relatively short period of time that is unequivocally specified in the federal health care reform statute.

Not only will every citizen and lawful resident eventually be entitled to health care, but they will also be required to register with a Health Alliance and pay the premium. If the government mandates that every American join a health plan, it has a corollary responsibility to ensure that financial assistance is afforded to those who truly cannot afford the premium. This requires "means testing," which raises a host of troubling questions. The most important questions are who has the right to be subsidized, at what level, and how is qualification to be determined? The subsidy level is important, since it must encompass as many individuals and families as possible who would find it a hardship to pay the health premium. Were the full subsidy to be provided only for persons at, for example, forty percent or less of the poverty line, with a sliding scale up to the poverty line, it would leave out many needy people. What legal and moral rights would government have to force payment of the premium? Could government withhold health care from those who did not pay ("free riders")? Consider the case of a young, healthy adult who decides not to register or pay a health premium. When that person becomes ill and seeks care, he or she will not be turned away. Instead, an attempt to register that person at the point of service will be required. This might well include penalties for failing to register and pay, as well as recovery of some past premiums.

Those who have watched the Medicaid system over a number of decades have described the disincentives and humiliation of the process of qualifying through means testing. ${ }^{34}$ Individuals who are asked many probing questions about their financial position, family, and other personal or health characteristics often do not come forward. They may be too embarrassed or confused by the process, particularly if they do not speak English or are of different cultural backgrounds. The simplest and most respectful method of means testing is through a negative income tax. ${ }^{35}$ Those eligible for subsidy might receive a subsidy that could be paid directly to the Health Alliance. The new health care system ought not to repeat many of the problems that have plagued other entitlement programs in the past.

The decision to limit health coverage to citizens and lawful residents also poses difficulties for universal access. Some safety net must be available to

34 See, e.g. Stephen H. Long \& John L. Palmer, Financing Health Care, in Income-Tested Transfer Programs: The Case for and Against 367, 398 (Irwin Garfinkel ed., 1982) (acknowledging that Medicaid recipients may feel stigma because of income testing). See generally, e.g., Lee Rainwater, Stigma in Income-Tested Programs, in Incomf. Tested Transfer Programs, supra, at 19.

35 Under a negative income tax, eligibility depends on income, not inclusion in a limited category of people. See Irwin Garfinkel, Introduction, in Income-Tested Transfer Programs, supra note 34 , at 1,4 . 
provide urgent care for persons who are not lawful United States residents and those who are lawful visitors. The new system will have to support essential service providers who offer uncompensated care. Further, in order to expand access, the new system should develop imaginative outreach programs, as well as statutory assurances of privacy, to encourage every eligible person to register for a health security card.

While President Clinton is committed to universal access to health care, many problems and complexities can inhibit full access to care. I have discussed only a few of the more obvious problems with finance and eligibility or registration requirements. Even if all of the financial impediments are addressed, many more non-financial barriers will stand in the way of true universal access. This raises the profound question of the future role of Health Alliances. Do they act merely as aggressive purchasers of services, or do they also help plan the delivery of services within their regions? To remedy lack of access and unequal quality, robust Health Alliances might have to be equipped to assess and act on service delivery issues. These include the distribution of primary, secondary, and tertiary care services; public health programs for vaccinating children to prevent infectious diseases; partner notification regarding sexually transmitted diseases; and directly observed therapy for tuberculosis.

\section{B. EQUITY}

Persistent and sometimes substantial differences exist in the quality of health care in the United States. ${ }^{36}$ Differences occur between the insured and the uninsured, ${ }^{37}$ the poor and the rich, ${ }^{38}$ those in public (e.g., Medicaid) and private programs, ${ }^{39}$ and between minority and white populations. ${ }^{40}$

While equality need not apply rigorously to the distribution of all resources in society, the right to equal health care has a special claim. For ethical reasons similar to those for access, health care represents a fundamental social good. Like education, health care is essential to a person's ability to participate fully in life's opportunities. A healthy population, like an educated population, is also beneficial to society. A two-tier system of health care, in which those in the lower tier receive clearly inferior and lower-quality services, perpetuates inequities among individuals and groups. These inequalities occur not only in attaining health but, indirectly, in attaining status, acceptance, and livelihood in society.

How might inequalities develop in a new health care system in which every citizen and lawful resident has the right to the same health benefits package? To some firm believers in managed competition, the only differences among health plans would be in the "frills" — as with, for example,

\footnotetext{
${ }^{36}$ For a discussion of this phenomenon, see Troyen A. Brennan, An Ethical Perspective on Health Care Insurance Reform, 19 AM. J. L. \& MED. 37, 42-43 (1993).

37 See Helen R. Burstin et al., Socioeconomic Status and Risk for Substandard Medical Care, 268 JAMA 2383 (1992).

38 See Wise et al., supra note 11.

${ }^{39}$ See Mark B. Wenneker et al., The Association of Payer With Utilization of Cardiac Procedure in Massachusetts, 264 JAMA 1255 (1990).

40 See Council on Ethical and Jud. Aff., supra note 12.
} 
health centers in nicer areas, with more pleasing decorations and shorter waiting times for non-emergency cases. They argue that these "extras" may make a health care experience more pleasant, but not more effective. Skeptics of managed competition argue that plans with consumers who pay higher premiums and come from higher socioeconomic groups will be inherently higher-quality plans. The added revenue and consumer insistence on high quality and broad choice will drive these plans to offer more health care professionals, including specialists, more qualified and experienced providers, better-equipped hospitals, more sophisticated machinery, better prevention services, and shorter waiting times for services. The result will be distinctly higher-quality care for populations who are already healthier. Those with greater income, moreover, will be able to purchase supplementary health insurance to provide services that are not covered or are inadequately covered in their health plan.

Ideally, subsidized persons would be fairly distributed among all plans from the least to the most expensive in the area of the Health Alliance. This goal might be achieved in several ways, although society ought to be clear that it probably will not remove all inequities from the health care system. ${ }^{41}$ The most likely option would be to limit the differential between the least and most expensive plans in the Alliance. This design principle, which might be called "banding," would prohibit any plan in the Alliance region from charging more than a set percentage over the benchmark plan. The lower the premium difference allowed, presumably the fewer the inequities. Banding might also restrain escalating health care costs by setting premium increases against the rate charged by the least expensive (but still high-quality) plan within the Alliance.

Depending on the size of the premium difference, however, differences in quality can and will occur. As the band between the least and most expensive plans expands, it may be assumed that inequality increases. Whatever differences in premium price are permitted to exist, another way to attain greater equity is in the subsidy afforded to low-income populations. If a subsidy only provides funding for the benchmark premium or less, it is virtually inevitable that all subsidized populations will be in the least expensive plan(s).

The most certain way to overcome inequity is also the most costly - to subsidize low-income individuals at the top rate of the banding level. For example, if a band of 20 percent is permitted between the least and most expensive plans in the Alliance, the federal government would set the subsidy rate at 120 percent of the benchmark premium. This would enable the poor to choose any plan in their geographic catchment areas. A generous subsidy,

41 For example, it is unlikely that any new system in America would prohibit people from buying a supplemental health benefits package with their own money. While many may argue that people can spend their money on any service they choose, there are inherent risks for the new health system. First, if persons can purchase services, they may be taking scarce resources from others in the new system. The most obvious examples involve truly limited resources, such as sophisticated equipment or vital organs. Could a private buyer jump the queue for a kidney transplant over a person who has been waiting in the system? Would society consider that just? Second, one must consider whether government should continue to subsidize health care purchases through tax deductions. Arguably, if persons choose to buy supplemental insurance, they should pay the full and real cost of these services. 
however, would require two trade-offs - cost and "inter-socioeconomic equity." Whatever the total cost of bringing the poor into the new system, it will rise by roughly the percentage of additional subsidy afforded. Providing a subsidy of 120 percent of the benchmark premium, for example, may raise total federal expenditures by up to 20 percent. This will require additional revenue sources, thereby placing greater burdens on taxpayers. The concept of "inter-socioeconomic equity" refers to the perceived fairness of allowing the poor and unemployed to jump the queue to the most costly plan in the Alliance. That plan may be beyond the reach of many working and middleclass individuals, who may perceive it as unjust for persons who are poorer than they, and who may not work, to obtain a "better" health plan.

Between the two extremes of a subsidy at the benchmark level and a subsidy tied to the most expensive plan would be a subsidy somewhere in the middle. In an Alliance that allowed a 20 percent band, for example, the federal subsidy would be set between 105 and 110 percent of the benchmark premium.

A final possible method of creating greater equality would be to issue rules that ensure a fair distribution of the subsidized populations. These would require each health plan to accept a certain percentage of subsidized individuals and families. The difference in cost could be made up by the Alliance, or each plan could distribute the cost among all of its consumers. In this latter scenario, more expensive plans could better afford to absorb the subsidized group.

In the absence of adequate safeguards, other features of the new system might perpetuate inequities. Consider, for example, the effect of a federal subsidy that was rigidly tied to the benchmark premium (as it may have to be for financial and political reasons). It is quite possible that some health plans will strongly compete to become the least expensive plan. Competition, of course, could be highly beneficial if plans competed on the basis of quality. Health plans, however, might set themselves up more like "Medicaid mills." They might reason that providing services in poorer areas could become quite lucrative because: (1) the new system would have developed a large market of consumers with a federally guaranteed payment to health plans; (2) poorer populations often are less likely to visit their physicians and seek sophisticated services than are more informed and wealthier consumers; and (3) managed care might provide an opportunity to design a plan that significantly impedes access to services.

Another consequence of a federal subsidy tied to the benchmark premium is that it limits choice so rigidly that it compromises a poor person's ability to act as an educated consumer. Poor people cannot "vote with their dollars" and choose another plan if the benchmark plan provides an unsatisfying experience. Subsidies tied to the benchmark premium might also jeopardize security and continuity of care because, as health plans compete to be the least expensive plan in the Alliance, new plans may become the benchmark from year-to-year. Subsidized patients may be obligated to change plans and physicians in order to move to the plan that happens to be the least expensive plan each year. The President's clear commitment to choice, security, and continuity of care should assure that these inequities and indignities 
for the poor never develop. However, competition of any kind (even if it is effectively managed) poses a risk to the poor who cannot compete.

One of the best guarantees of equity will be the national requirement for community rating. The question arises, however, as to how "the community" is defined. The more the system allows groups to "opt out," the greater the risk to the concept of community rating. Large employers with a thousand or more employees may be able to opt out of the new system. While they probably will be required to community rate, their "community" would be limited to their own employees. Industries with a younger, wealthier, and healthier workforce would have a strong incentive to self-insure or form their own Alliance. This is certainly not disadvantageous for employees of those companies who may receive a more generous benefits package at lower cost. It might, however, "skim off" segments of healthy populations within an Alliance area, leaving the Alliance to cover a smaller, less healthy population. Opt-outs for large companies may be a political necessity to obtain the support of large corporations and trade unions, but these trade-offs will negatively affect the equity of health care coverage.

\section{Justice}

A just health care system incorporates both substantive and procedural aspects of justice. Distributive justice requires a fair sharing of benefits and burdens. A just distribution of benefits and burdens does not require an equal sharing; when individuals with different needs and means receive the same level of services and pay the same, the system is distinctly unjust.

Benefits of health care must be distributed on the basis of need: those with greater needs receive greater services. A needs-based system ensures that those who are ill receive all reasonable services to restore their functioning and relieve their pain and suffering. It must also be open and accountable, and provide due process for individuals or groups who are denied benefits.

For these reasons, the governance of Health Alliances and AHPs is of central importance to consumers of health services. Health Alliances will be quasi-governmental organizations that exercise fundamental powers on behalf of the state. The activities of Health Alliances powerfully affect the interests of consumers: (1) Financial - the honesty and effectiveness of Health Alliances as purchasing agents directly affect the cost and quality of health care; if Health Alliances contract with AHPs that have inflated costs or inferior-quality services, consumers are harmed; (2) Quality assurance - the rigor with which Health Alliances monitor the quality of health plans and publish the results will affect the health and safety of consumers; (3) Autonomy - the amount of useful information about health plans published by Health Alliances directly affects the ability of consumers to make informed choices among competing health plans.

Health Alliances carry out the functions of government in these and other meaningful ways. The more Health Alliances act like government, the more important openness and public accountability to consumers become. The concept of open and accountable governance does not indicate consumer ownership. Rather, it requires direct or indirect electoral accountabil- 
ity so that appointments are made by the governor or other elected officials; formal mechanisms are in place for meaningful consumer participation in decisionmaking; and Alliances publicly disclose information about their financing and operations.

Health plans do not act like government in the same way as Alliances, yet they do have equally powerful effects on the interests of consumers of health services. They are also much closer to the community and the daily lives of consumers. Consumer participation in governance becomes more meaningful at the local level, where decisions affect individuals and groups who seek quality health care. If consumers are dissatisfied with their health plans, many will have the opportunity to move to another plan. Some consumers, however, will not have the same opportunities for choice. There may only be one, or very few, plans in some rural communities, and poorer or subsidized populations may not be able to afford to join another plan. Where choice is limited, the case for effective participation in governance and decisionmaking becomes stronger.

As health services are delivered within health plans, disagreements and disputes will inevitably arise among consumers, health care providers, and administrators. There are many reasons why it is important for the new health care system to anticipate conflict and design structures and procedures to resolve conflicts and adjudicate disputes. There is an intrinsic value to fair procedures for individuals and groups who are adversely affected by decisions involving their health care. ${ }^{42}$ The due process right to be heard allows aggrieved persons to influence the decisionmaking process, "an opportunity that expresses their dignity as persons."43 Regardless of the outcome, the intrinsic value of a due process hearing derives from participation in a decision that affects the person and the knowledge of reasons for that decision. ${ }^{44}$

Fair procedures are also warranted as a means of arriving at a reliable outcome that is based on full and accurate information and consistent standards. With a fair hearing, an impartial decisionmaker, guided by objective criteria, can assemble all of the relevant evidence and come to a more informed conclusion. The trade-off for establishing fair procedures (depending on how elaborate they are) is the introduction of a formalized, adversarial system, with its added complexities, costs, and delays.

The design of thoughtful alternative dispute resolution procedures for each health plan can help avoid litigation. Ultimately, however, aggrieved individuals need access to courts and a fair hearing. At the same time, some courts may have a bias in favor of ordering the provision of treatment even when the cost is extremely high and the benefits unestablished. If managed care is going to work, consumers ought not to be afforded a right to any and all treatments they may desire.

In the end, a just system is measured by how fairly it distributes the benefits of health care and the costs of paying for it, as well as the way in which it operates - with integrity, objectivity, openness, and fair procedures. The

42 Professor Laurence Tribe discusses the notion of intrinsic value in the due process right to be heard in Laurence H. Tribe, american Constitutional Law 666-67 (2d ed. 1988).

43 Id. at 666.

44 See id. 
new health care system should distribute scarce resources on the basis of need and the benefits to be accrued from treatment; it should distribute the burdens based primarily on the ability to pay; and it should be publicly accountable and fair in its dealings with consumers.

\section{Choice}

For many consumers and physicians, the concept of "choice" has become the critical yardstick with which to measure a new health care system. The importance of protecting, respecting, and making effective individual choices has strong ethical roots in the literature of health reform and ethics. The ethical principle of respect for persons recognizes people as autonomous agents and requires that their choices be observed.

"Choice," however, is a much more complicated concept in the health care reform debate. Choice can refer to access to health care generally, to health plans, to health care providers, or to treatments. In each case, the concept of choice is fraught with complexity and trade-offs. A decision to afford more choice to certain persons for certain purposes can deny choice to other persons for other purposes.

The choice of whether or not to receive health care is restricted by a person's ability to pay, as well as non-financial barriers. Providing a legal entitlement to health care, with a federal subsidy for those unable to afford health care, ensures choice at a fundamental level. However, the choice of plans, providers, or treatments can arise only after a person gains access to the health care system. If guaranteeing choice to all patients who already have health care means denying access to others, would this provide a net increase, or diminution, of choice? Managed care, for example, usually diminishes a person's choice of physicians, but costs less than fee-for-service plans. If the health care system could provide universal access to health care, thereby making greater use of managed care, it would increase choice for some and decrease it for others.

Choice can also be measured by the number of opportunities to choose among competing health plans. Used in this way, choice is enhanced by having a number of competing plans that offer quality services. Informed choice is also enhanced by full and accurate information about the costs and quality of the services that plans offer. Managed competition, properly designed and implemented, can facilitate choice among plans. ${ }^{45}$ In some areas, however, the size of the population would not support more than one plan, and some poorer consumers would not be able to afford to choose more costly plans. In these situations, financial constraints may prevent us from offering choice.

Most people define "choice" as the right to select a primary care physician or a specialist when they need medical attention. Underlying this definition is the great reliance that they place on the trust established in a physician-patient relationship. Moreover, educated American consumers often believe that they can accurately select physicians with greater qualifications and experience. A great deal of choice, understood in this sense, is built

\footnotetext{
45 Some employers in the present system impose managed care on employees, thereby depriving them of a choice of health plan.
} 
into the President's plan for the health care system. Choice of physicians will be ensured at several levels: (1) one free-choice-of-provider, fee-for-service plan is likely to be present within each Health Alliance; (2) consumers will be entitled to register with the plan that includes their personal physician, and can transfer if their physician leaves the plan; and (3) if a consumer does not have a personal physician, he or she will be able to choose one from among those offered by health plans, using detailed information about the physicians' backgrounds and experience. Choosing a physician through a freechoice-of-provider indemnity plan should accurately reflect the true costs of that unfettered choice. Health Alliances can help control costs by inviting competitive bidding to select one insurer to operate a fee-for-service plan.

At first glance, giving patients a choice of treatments may appear relatively uncontroversial. The doctrine of informed consent appears to guarantee patients full information about treatment alternatives and the right to determine their preferred course of treatment. While it may be true that competent patients have the right to decline any treatment, it does not follow that informed consent affords a right to any treatment that the patient chooses. In fact, a patient's treatment choice is constrained by many factors; the new system would merely carry over many current limits and may increase limits in other areas. Currently, the Food and Drug Administration ("FDA") must approve pharmaceuticals; the physician must believe the treatment is beneficial (e.g., physicians may not offer off-label uses for some drugs); and insurers must agree to pay for the treatment (e.g., companies may refuse to reimburse for experimental treatments). Conflicts regarding patients' treatment choices have occurred in a variety of settings, and have involved persons with AIDS or other incurable conditions who were seeking access to unapproved therapies that offered a slim hope of relief or recovery, ${ }^{46}$ as well as patients and family members who were seeking "futile" treatments, such as life support, for persons in a persistent vegetative state. ${ }^{47}$

Patients have expressed particular concerns about treatment limitations imposed under managed care systems. While there is little evidence that it offsets quality, the increased use of managed care under the new system may lead to added worries about limits on treatment choice. Additionally, the National Health Board may issue practice guidelines that limit or eliminate the use of certain treatments that are costly and offer little or no benefit.

The features of the new system designed to save money by limiting the use of less effective and more costly treatments (e.g., practice guidelines and managed care) will restrict choice to some extent. In doing so, the system may use the resources that are saved to guarantee choice in other areas and improve overall quality.

\section{CONCLUDING REMARKS REGARDING U.S. HEALTH CARE REFORM}

The ethical values of access, equity, justice, and choice are of central importance in measuring President Clinton's plan for a new health care system.

\footnotetext{
${ }^{46}$ See, e.g., Weaver v. Reagan, 886 F.2d 194 (8th Cir. 1989).

${ }^{47}$ See, e.g., Cruzan v. Director, Missouri Dept. of Health, 497 U.S. 261 (1990)
} 
Many who have written about and advocated health care reform might agree with these evaluative standards, but choose to compare the President's plan to a single-payer system, like Canada's, rather than to the status quo, as I have done. Certainly, a single-payer system might achieve the goals of health care reform as well as - or better than - the form of managed competition with a budget that has emerged from the Presidential Task Force. However, a single-payer system imposed by the federal government may not be politically feasible without support from the President. In fact, it may never have been feasible given the deeply entrenched American patterns that tie health care to employment and the insurance industry.

The years 1993-1994 may produce the most important domestic social reform since the New Deal. President Clinton's plan, even with its trade-offs and limitations, can produce enormous social good for millions of Americans by enhancing their access to care, reducing the inequities in the health care system, allocating benefits and burdens more justly, and expanding choice along many dimensions. As years of careful thinking and writing on health care reform turn into a season of political debate and decision, the ethical dimensions regarding the value of health care in the daily lives of Americans need to be carefully weighed.

\section{IMPLEMENTING U.S. HEALTH CARE REFORM: A SYMPOSIUM}

The distinguished authors in this Symposium prepared their Articles in advance of the Presidential Task Force's proposal, and bring a great deal of clarity and insight into the central issues that will emerge from the debate on health care reform. All contribute important perspectives to the nationwide dialogue that invariably accompanies reform of this magnitude.

The first Article is written by Princeton economist Uwe E. Reinhardt. In Reforming the Health Care System: The Universal Dilemma, Professor Reinhardt takes an all-embracing view of the worldwide problems in health care delivery. He then examines the economic and social peculiarities of the United States that have thus far prevented major reform. Professor Reinhardt's conclusion recognizes the prevailing trends in the United States and other industrialized nations. He identifies a worldwide standard of health care delivery toward which all health systems appear to be converging. Following Professor Reinhardt's economic perspective, Professor Troyen Brennan of the Harvard School of Public Health presents An Ethical Perspective on Health Care Insurance Reform. Professor Brennan, a medical practitioner, draws on the ethical imperatives that are ingrained in the medical profession for guidance in molding and implementing today's health insurance reforms.

The next three Articles examine specific health insurance reform proposals and their feasibility as components of a comprehensive, nationwide reform package. In Canadian Medicare: Can It Work in the United States? Will It Survive in Canada?, Professor Raisa Deber of the University of Toronto dispels some popular myths about the Canadian system and identifies how its present constraints would translate in the United States. Professors Timothy Jost and Sandra Tanenbaum from the Ohio State University School of Law propose ways to obtain broad-based acceptance of a single-payer, global budget system in their Article, Selling Cost Containment. Their proposal is especially perti- 
nent to the nationwide support that will be necessary to implement the Clinton plan. Finally, in Regulation and Federalism: Legal Impediments to State Health Care Reform, Professor Wendy Parmet of Northeastern University School of Law details the basis for and barriers to state-based initiatives in health insurance reform. Her discussion is important in light of the Clinton plan's increase in state flexibility to act as "laboratories" for health insurance reform.

Two supplemental pieces, a student Note by Boston University School of Law's Ronald Wisor, Jr., and a book review by Widener University School of Law Professor Barry Furrow, narrow the Symposium's focus even further to consider specific aspects of health care delivery in the United States. In Community Care, Competition and Coercion: A Legal Perspective on Privatized Mental Health Care, Mr. Wisor examines the privatization of mental health care, while Professor Furrow's Guest Book Review: Cystic Fibrosis and DNA Tests evaluates a report by the Office of Technology Assessment ("OTA") on genetic screening for cystic fibrosis. With the OTA's study of one disease and its examination of health insurers' attitudes about screening technologies, Professor Furrow brings the Symposium full circle. He discusses the competitive priorities that shape today's health insurance market, and further highlights the importance of implementing nationwide health care reform. 